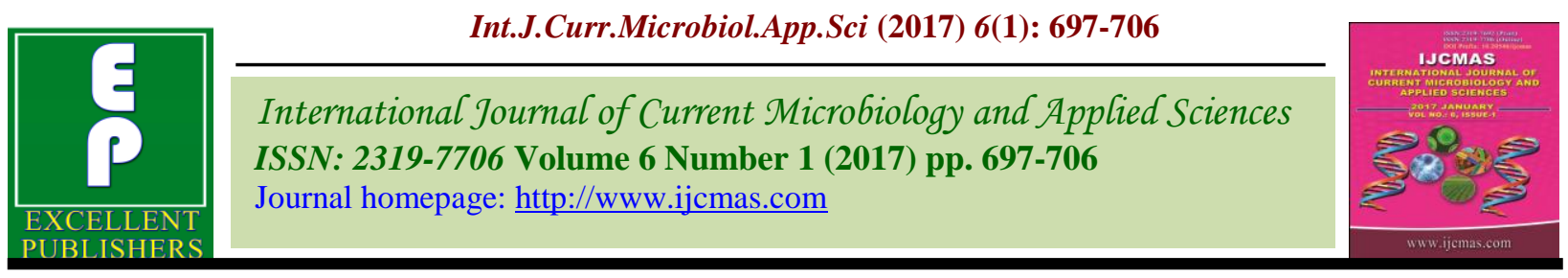

Original Research Article

http://dx.doi.org/10.20546/ijcmas.2017.601.084

\title{
Evaluation of Pyrus pashia Leaf Extract as a Disinfectant for Rainbow Trout (Oncorhynchus mykiss) Fertilised Eggs
}

\author{
Ravindra $^{1}$, Suresh Chandra ${ }^{2}$, S.K.Mallik ${ }^{3}$ and R.S.Patiyal ${ }^{3}$ \\ ${ }^{1}$ ICAR-National Bureau of Fish Genetic Resources, Canal Ring Road, P.O.-Dilkusha, \\ Telibagh, Lucknow-226002, Uttar Pradesh, India \\ ${ }^{2}$ ICAR-Directorate of Coldwater Fisheries Research, Experimental Field Centre, Champawat, \\ Uttarakhand, India \\ ${ }^{3}$ ICAR-Directorate of Coldwater Fisheries Research Bhimtal-263136, Uttarakhand, India \\ *Corresponding author
}

\begin{tabular}{|l|l}
\hline \multicolumn{1}{l}{ A B S T R A C T } \\
\cline { 1 - 1 } $\begin{array}{l}\text { Keywords } \\
\begin{array}{l}\text { Rainbow trout, } \\
\text { fertilised egg loss, } \\
\text { hatchery incubation, } \\
\text { disinfectant, } \\
\text { leaf extract, } \\
\text { Pyrus pashia }\end{array}\end{array}$ & $\begin{array}{l}\text { In hilly areas, local population with their traditional knowledge utilize } \\
\text { several medicinal herbs and plants parts for treating injuries and aliments of } \\
\text { their livestock, agricultural crop and human population. Among these Pyrus } \\
\text { pashia, commonly known as Indian pear or Mehal is hardy wild mid hill } \\
\text { fruiting tree. Crude leave extract traditionally used for treating infection of } \\
\text { toe finger particularly during rainy season. Fruit juice and ripe fruits of } P . \\
\text { pashia used for treating eye injury and mouth sours. With a view to } \\
\text { minimize use of chemical disinfectant in hatchery and to find out a locally } \\
\text { available suitable herbal substitute for disinfecting trout eggs, present } \\
\text { comparative study was undertaken to observe the effect of leaves extract of } \\
\text { Article Info }\end{array}$ \\
\hline $\begin{array}{l}\text { Accepted: } \\
\text { 29 December 2016 } \\
\text { Available Online: } \\
\text { 10 January 2017 }\end{array}$ & \begin{tabular}{l} 
Pyshia on egg survival and hatching during incubation phase. \\
\hline
\end{tabular}
\end{tabular}

\section{Introduction}

Among cultivable coldwater fishes, rainbow trout, Oncorhynchus mykiss contributes substantially in upland aquaculture production in India (Vass 2012). The species is widely preferred for farming owing to its hardy nature, tolerance to wide temperature fluctuations and simple breeding protocol (FAO 2012). Fertilised egg of rainbow trout takes a long incubation period of 3-14 weeks for hatching under varied thermal regimes (Woynarovich et al., 2011). Factors like lower sperm motility, over- ripening / untimely egg tripping, poor egg quality, physical injury handling and microbial infection greatly influence fertilisation and survival of eggs during hatchery incubation. Exposure of trout eggs to direct light or higher illumination for longer period during incubation, fungal infections and frequent disturbance of eggs in rearing troughs may also reduce survival of eggs and fry (Bell et al., 1971; Barker et al., 1989; Griffiths 1991; Shepherd and Bromage 1992). Environmental parameters like temperature, $\mathrm{pH}$, dissolved Oxygen, ammonia 
etc. also plays important role in spread of infections and survival of eggs. Bacteria to some extent are responsible for salmon egg loss under a complex interaction between eggs, microbes and water quality parameters (Shepherd and Bromage 1992). During various developmental stages of eggs in hatchery, under unhygienic conditions, opportunistic and pathogenic microbes inhabit over the eggs surfaces, thus, chances of egg damage increases many folds (Barker et al.,1991). Although, higher survival of trout eggs in hatchery could be achieved by selection of healthy brooders, maintaining optimum water quality parameters (Woynarovich et al., 2011). However, during egg incubation phase, heavy loss of eggs has been reported due to microbial infections (Anon 2013). With growing rainbow trout farming in mid hill areas, demand for rainbow trout fingerlings is also rising day by day. To meet increasing seed demand, more numbers of eggs are incubated in unit area, thus chances of infection also increases several times (Jeff et al., 2005). Improving water quality supply of hatchery and maintaining cleanness in egg rearing troughs through regular removal of dead and decayed eggs, shells and other substrates help in reducing egg loss. However, in commercial trout seed production units, practically it is not always possible to maintain all the desired parameters under optimum range. To maintain optimum hygienic conditions, various anti fungal and antibacterial chemicals have been tested in trout hatcheries with varying degree of protection. This includes malachite green, formaldehyde, iodine, hydrogen peroxide, bronpol and sodium chloride (Wanger et al., 2008). Malachite green was earlier considered as one of the strong antifungal agent for treating fish eggs. However, malachite green was banned worldwide in year 2002 owing of its harmful effects on animal health (Van West 2006). Exposure of incoming hatchery water, by U.V radiation significantly reduce trout egg loss in hatchery (Heikkinen et al., 2013). At the same time, studies has also revealed that ozone (Forneris et al., 2003), $\mathrm{H}_{2} \mathrm{O}_{2}$ (Gaikowski et al., 1998) and UV radiation (Heikkinen et al., 2013) may decrease egg hatching percentage during trout eggs incubation. To achieve better egg survival, antibiotics are also used. Unregulated use of chemicals and antibiotics in fish hatcheries and farms elicit harmful effects on fish and aquatic environment. Negative effect of several chemicals and antibiotics used in hatcheries are well known. With increasing awareness towards these effects, safe methods are being explored to minimize such losses and their side effects (Srinivasan et al., 2001). Many herbal extracts or paste for curing health disorders are now widely being preferred and have been tried in treating fish health disorders (Madhuri et al., 2012a; Pandey et al., 2012b; Dey and Chandra 1994, 1995; Ramasamy et al., 2011). In hilly areas, local population with their traditional knowledge utilize several medicinal herbs and plants parts for treating injuries and aliments of their live stock, agricultural crop and human population (Negi et al., 2011). These plants contain active ingredients which act as antimicrobial and antifungal agents. Among these Pyrus pashia (Buch-Ham ex D.Don), commonly known as Indian pear or Mehal is hardy wild mid hill fruiting tree belongs to family Rosaceae and found in the mid Himalayan areas. The tree generally grows on sandy loamy soil at a temperature range from -10 to $35{ }^{0} \mathrm{C}$. The bark leafs and fruits are traditionally used both for consumption and also as medicine (Jambey et al., 2012). Strong antioxidant activity with free radical scavenging activity has also been reported in flower extract of P. Pashia (Jianmin Hea, 2015). Crude leave extract traditionally used for treating infection of toe finger particularly during rainy season. Fruit juice and ripe fruits of $P$. pashia used for treating eye injury and 
mouth sours (Negi et al., 2011). With a view to minimize use of chemical disinfectant in hatchery and to find out a locally available suitable herbal substitute for disinfecting trout eggs, present comparative study was undertaken to observe the effect of leaves extract of $P$. pashia on egg survival and hatching during incubation phase.

\section{Materials and Methods}

Plant material: $P$. pashia is an angiosperm commonly known as Mehal or Mol in Hindi. The tree is widely distributed in mid Himalayan areas in between 750-2600 msl and generally grows to a height of 3-6 m in sandy loamy soil. Although, small pear shaped fruits are edible but, they do not fetch any market price and mostly consumed by wild animals. Locally crushed green leaves extract is used traditionally by hill people for curing infections of toes.

Preparation of disinfectants: Newly budding reddish green leaves of $P$. pashia were collected from the trees located in fish farm of ICAR-DCFR Field Centre, Champawat in Uttarakhand state of India, located at an altitude of $1620 \mathrm{msl}$. Collected leaves were washed thoroughly in tape water and then allowed to dry under shade for 10 days. After complete drying, leaves were grinded and 200 $\mathrm{g}$ fine powder was made. The powder was soaked in $800 \mathrm{ml} \mathrm{100 \%} \mathrm{ethanol} \mathrm{and} \mathrm{placed} \mathrm{in}$ a shaking incubator for 24 hours. Soaked leaves powder in the above solvent was filtered through $20 \mu$ mesh size filter paper. Filtered extract then placed on rotary evaporator and evaporated till volume reduced to $200 \mathrm{ml}$. The solution stored in fridge in air tight bottles at $4^{0} \mathrm{C}$ temperature. Before using the extract for egg disinfection, a $100 \mathrm{ml}$ solution of leave extract was diluted with $900 \mathrm{~mL}$ of distilled water to make it $10 \%$ and further concentration made accordingly (Lin et al., 1999). Pyrus pashia was prepared from naturally dried fallen leaves and above methodology was followed for preparing extract of the dry leaves. Stock solution of iodine named Betadine (Povidone iodine) containing $0.5 \% \mathrm{w} / \mathrm{v}$ iodine (Win Medicare) was procured from the local market and diluted to a concentration of $100 \mathrm{mg} / \mathrm{l}$.

Rainbow Trout Egg Striping: Mature healthy rainbow trout brooders with mean weight/length of $679.90 \pm 11.97 \mathrm{~g} / 371.00$ $\pm 11.10 \mathrm{~mm}$ were randomly collected from brooder raceways and brought to hatchery for stripping. Approximately 35,000 nos. of eggs were realized from 23 nos. of female rainbow trout brooders. The milt was poured over the eggs and kept for 15 minutes in dark conditions to accomplish adequate fertilization. All batches of fertilized eggs were mixed together to get uniformity of egg stock. For different treatment, initially fertilized eggs were equally divided in four trays.

Disinfection of trout eggs: Following standard methods of egg disinfection, fertilized eggs were exposed in three treatments (Anon 2009). Before adding water in fertilized eggs, egg of first tray/trough were exposed in $10 \%$ green leaves extract (GL) for 15 minutes, washed thoroughly in hatchery water and equally divided in three rearing troughs @ 2500 $\pm 250 /$ trough for further incubation. Fertilized eggs of second tray were similarly exposed in $10 \%$ prepared dry leaves extract (DL) for 15 minutes, washed and equally placed in three troughs @ $2500 \pm 250 /$ trough. Eggs of third troughs dipped in $100 \mathrm{mg} / \mathrm{L}$ Iodine solution (I) for 15 minutes, washed and placed in three troughs @ 2500 $\pm 250 /$ trough for incubation. The dose in GL, DL was arrived through earlier observations made in hatchery under similar conditions. Eggs of fourth trough were thoroughly washed in tape water and transferred to incubating troughs measuring 
$45 \times 45 \times 18 \mathrm{~cm}$ in size in replicates and kept as control without any exposure. These egg rearing troughs were placed over horizontal rectangle FRP tub $(225 \times 50 \times 21 \mathrm{~cm}$ size $)$ with a holding capacity of four egg troughs/tub. Normal water flow rate of $6-8 \mathrm{~L} / \mathrm{min}$ was maintained during egg incubation period. Daily egg damage in each trough was recorded for 42 days (6th week) till hatching of the eggs. Uniformity in hatching of egg also recorded.

Physicochemical Parameters: Water quality parameters of experimental troughs were analyzed at fortnightly intervals while water temperature recorded every day to ascertain variation of limiting important parameters. Water parameters were analyzed by WTO15 Multi-water Parameters Testing KIT-HI Media and Dissolved Oxygen by Winkler method. Dead and decomposed eggs were routinely taken out from all the $12 \mathrm{egg}$ incubation troughs and counted. At fortnightly intervals, rectangle egg rearing troughs were cleaned without disturbing eggs to maintain optimum rearing conditions for the developing eggs.

Statistical analysis: Mean value of parameter were subjected to one-way analysis of variance (ANOVA) to study the treatment effect and Duncan's Multiple Range Tests (DMRT) were used to determine the significant differences between the mean value. Comparisons were made at $5 \%$ probability level. All the data were analyzed using statistical package SPSS (Version 16) (SPSS Inc., Chicago, IL, USA).

\section{Results and Discussion}

In three exposures and control, numbers of weekly egg damage in each rearing troughs was studied. Mean egg damage in green leaves extract (GL) was significantly lowest $(\mathrm{P}<0.05)$ in I, II and VI week of incubation however, in III week, no difference in egg loss was recorded in all three exposures and in control troughs. Except II, III and V week, Iodine exposed eggs showed significantly higher egg loss. DL exposed egg showed significantly lower egg loss only in II week. Mean percent egg loss under three exposures and control is presented in Table-1. Total mean percent egg loss is given in Fig-1. Physicochemical parameters (Table-2) remained under normal limits. However, water temperature of hatchery varied between 5.0-11.5 ${ }^{0} \mathrm{C}$ (Fig-2). Highest mean \pm SE hatching percent of $62.66 \pm 4.33$ observed in GL treated eggs followed by $42.00 \pm 5.80$ in C, $35.33 \pm 3.17$ in DL and 15.66 \pm 4.04 in I (Table 3).

The major objective of this study was to find out suitability of locally available plants leaves extract for disinfecting trout eggs. Among various plants, Pyrus pashia is widely found in mid Himalayan areas and grows in sandy loamy soil. During rainy season, mid hill local people commonly uses crumpled green leaves extract of $P$. pashia for healing of Athlete's foot disease which is assumed to be of a mixed fungal and bacterial etiology having high resistance against common antibacterial and antifungal medicines. Fertilized eggs of rainbow trout (Oncorhynhus mykiss) under water temperature range of $3.9-14.4^{\circ} \mathrm{C}$ takes a long period from 21-100 days (Woynarovich et al., 2011). During this prolonged incubation period, fertilized eggs constantly come in contact of diverse environmental and microbial organism. With elongation of incubation period, chances of egg damage increases many folds due to growth and colonization of bacteria and fungus over the eggs in rearing facilities. A number of occasions, higher load of microbes also get entry through stream water which is normally maintained @t 6-8 L/minute (7200-10080 L/day) in rearing troughs. In flow- through 
hatcheries system, where retention of incoming water is for a shorter duration, effective control of microbial infections is a major problem. Large egg scale loss with wide fluctuations in environmental parameters in a rainbow trout hatchery has been reported (Anon 2013). Several external disinfectants like malachite green, iodine, hydrogen peroxide, bronopol, salt, formalin, UV radiation and herbal extracts have been tried to control such infection with varying degree of success. (Kimura et al., 1976; Mitchill and Collins, 1997; Wanger et al., 2008; Jambey et al., 2012). Under present observation, compared to non treated control group (C) where egg damage was $12.81 \%$, egg damage in dry leaves extract (DL) and iodine (I) was significantly higher and was $15.28 \%$ and $23.90 \%$ respectively. However, green leaves extract (GL) showed significantly $(\mathrm{p}<0.05)$ lower total percent egg mortality of $4.61 \%$ till $6^{\text {th }}$ week of incubation indicating probable minimization of external infections in eggs. The green leaves extract (GL) of P.pashia helped in reduction of egg loss in initial weeks when likelihood of infection spread is more thus, gave higher survival rate. This may primarily be attributed to presence of phenolics alkaloids, and saponins compounds in leaf extract of $P$. pashia which might be helping in inhibition of microbial infection particularly in initial weeks of incubation. Through disc diffusion test, antibacterial activity of $P$. pashia against Klebsiella pneumonia, Shigella flexneri and Escherichia coli has been demonstrated (Saklani and Chandra 2012). Antioxidant activity and presence of phenolic compounds in edible flowers of $P$. pashia has also been evaluated by researchers (Hea et al., 2015). Saponins compound found in many herbs act as antibacterial agent and herb, Sorghum Bicolor containing saponins compounds exhibits antibacterial activity against gram+ bacteria (Soetan et al., 2006). Same may be true in case of P. pashia extract. Apparently, normal development in GL exposed eggs in rearing troughs observed. Iodine (I) treated eggs showed highest percent egg loss in present study followed by DL treated eggs (Table 1). Dry leave extract (DL) of P. pashia was prepared by picking dropped old leaves which got exposed to direct sunlight and rain and then extract was prepared. The DL did not showed higher survival compared to control ones probably due to prior exposure of leaves in rain and sun resulting to leaching of beneficial bactericidal compounds like saponins and other alkaloids (Fig1). Microbial killing takes place either due to oxidation or halogenations of microorganisms (Bandrick et al., 1967) in iodine treated fertilized eggs. Groups of I treated fertilized eggs showed maximum egg mortality during incubation period. Iodophors are considered as a reliable disinfects in egg treatment in hatchery (Wade and Michael, 1967) and adequate dose and exposure period gives better survival in rainbow trout eggs (Fowler and Banks, 1991). Un-rinsed fertilized eggs were used under present study for exposing fertilized eggs in iodine solution. Lower retention of iodine in unrinsed fertilized eggs with lower dose might be the probable reason for higher egg loss. Similar to our observation immediate decline of iodine in unrinsed eggs has been reported in earlier study conducted by Chapman and Rogers 1992. Although, chances of iodine toxicity may not be the possible reason for egg mortality in present observation as $100 \mathrm{mg} \mathrm{L}^{-1}$ dose of iodine is not harmful for rainbow trout eggs (Amend 1974; Wanger et al., 2008). However, study of Wright and Snow 1975, demonstrated that lower dose of iodine was not able to inhibit Aeromonas liquefacience growth over the eggs and higher dose of $200 \mathrm{mgL}^{-1}$ only could control the infection. In hatchery troughs, fertilised eggs which encounter frequent water temperature variations due to lower water volume appear to make them more sensitive under intensive rearing. Usually 35-45 days 
are taken at water temperature range of 5-11.5 ${ }^{0} \mathrm{C}$ for hatching at Champawat hatchery in flow through system, however damaged unremoved eggs sometime act as a substrate for bacterial and fungal growth. It was found that with progression of hatching period, accumulation of organic residues below the troughs bottom resulted in rapid multiplication of organisms and thus in this process, higher egg loss has been observed.

Table.1 Mean percent \pm SE trout egg loss under three exposures and control. Mean values bearing different superscript in a column differ significantly $(\mathrm{P}<0.05)$

\begin{tabular}{|l|l|l|l|l|l|l|l|}
\hline S. No. & Treatment & \multicolumn{5}{|c|}{ Mean \% SE egg loss during different weeks of } \\
& & & \multicolumn{5}{|c|}{ incubation } \\
\hline & Week & I & II & III & IV & V & VI \\
\hline 1. & Green leaves Extract & $0.34^{\mathrm{c}}$ & O.53 & $0.75^{\mathrm{a}}$ & $0.67^{\mathrm{c}}$ & $0.88^{\mathrm{b}}$ & $1.44^{\mathrm{c}}$ \\
& (GL) & \pm 0.05 & \pm 0.08 & \pm 0.08 & \pm 0.14 & \pm 0.10 & \pm 0.13 \\
\hline 2. & Dry Leaves Extract & $3.07^{\mathrm{ab}}$ & $1.12^{\mathrm{c}}$ & $5.16^{\mathrm{a}}$ & $1.11^{\mathrm{bc}}$ & $1.68 \mathrm{ab}$ & $3.14^{\mathrm{b}}$ \\
& (DL) & \pm 0.15 & \pm 0.02 & \pm 2.12 & \pm 0.17 & \pm 0.01 & \pm 0.09 \\
\hline 3. & Iodine (I) & $4.24^{\mathrm{a}}$ & $1.75^{\mathrm{b}}$ & $6.40^{\mathrm{a}}$ & $1.41^{\mathrm{ab}}$ & $3.4^{\mathrm{a}}$ & $6.70^{\mathrm{a}}$ \\
& & \pm 0.68 & \pm 0.13 & \pm 2.76 & \pm 0.04 & \pm 1.40 & \pm 0.30 \\
\hline 4. & Control(C) & $2.40^{\mathrm{b}}$ & $2.36^{\mathrm{a}}$ & $1.20^{\mathrm{a}}$ & $1.65^{\mathrm{a}}$ & $1.15^{\mathrm{ab}}$ & $4.05^{\mathrm{b}}$ \\
& & \pm 0.17 & \pm 0.31 & \pm 0.14 & \pm 0.22 & \pm 0.074 & \pm 0.47 \\
\hline
\end{tabular}

Table.2 Weekly physicochemical parameters range during hatchery incubation of eggs

\begin{tabular}{|c|c|c|c|c|c|c|}
\hline Parameter & I & II & III & IV & V & VI \\
\hline $\begin{array}{c}\text { Air temp } \\
\text { Min/Max }\end{array}{ }^{0} \mathrm{C}$ & $8.0-11.0$ & $8.5-11.3$ & $6.5-14.5$ & $8.0-14.5$ & $10.0-16.0$ & $16.0-18.0$ \\
\hline $\begin{array}{c}\text { Water Temp } \\
\text { Min/Max. }{ }^{0} \mathrm{C}\end{array}$ & $5.4-7.2$ & $7.5-8.5$ & $7.0-8.0$ & $8.0-9.1$ & $8.8-10.6$ & $11.0-11.5$ \\
\hline $\mathrm{pH}$ & $7.0-7.8$ & $7.0-7.2$ & $7.0-7.3$ & $7.0-7.2$ & $7.1-7.2$ & $7.0-7.2$ \\
\hline DO(ppm) & $7.5-8.0$ & $7.5-8.0$ & $6.5-7.2$ & $7.5-8.0$ & $7.0-8.5$ & $6.6-7.2$ \\
\hline Hardness(ppm) & $25-30$ & $25-30$ & $25-30$ & $25-30$ & $25-30$ & $25-30$ \\
\hline Iron(ppm) & $0.1-0.2$ & $0.2-0.3$ & $0.2-0.3-$ & $0.1-0.2$ & $0.1-0.2$ & $0.2-0.3$ \\
\hline Nitrate(ppm) & $0.1-0.2$ & $0.1-0.2$ & $0.1-0.2$ & $0.2-0.3$ & $0.2-0.3$ & $0.1-0.2$ \\
\hline Chloride (ppm) & $30-40$ & $30-40$ & $30-40$ & $30-40$ & $20-30$ & $20-30$ \\
\hline
\end{tabular}

Table.3 Percent egg hatching on first day. Mean values bearing different superscript in a column differ significantly $(\mathrm{P}<0.05)$

\begin{tabular}{|l|l|l|c|}
\hline S. No. & Treatment & $\begin{array}{l}\text { Mean \% egg hatching } \\
\text { on first day }\end{array}$ & SD \\
\hline 1. & Green leaves Extract (GL) & $62.66^{\mathrm{a}}$ & \pm 4.33 \\
\hline 2. & Dry Leaves Extract (DL) & $35.33^{\mathrm{b}}$ & \pm 3.17 \\
\hline 3. & Iodine (I) & $15.66^{\mathrm{c}}$ & \pm 4.04 \\
\hline 4. & Control(C) & $42.00^{\mathrm{a}}$ & \pm 5.80 \\
\hline
\end{tabular}

Fig.1 Total mean percent egg loss under three exposures and control. Bars with different superscripts differ significantly $(\mathrm{P}<0.05)$ 


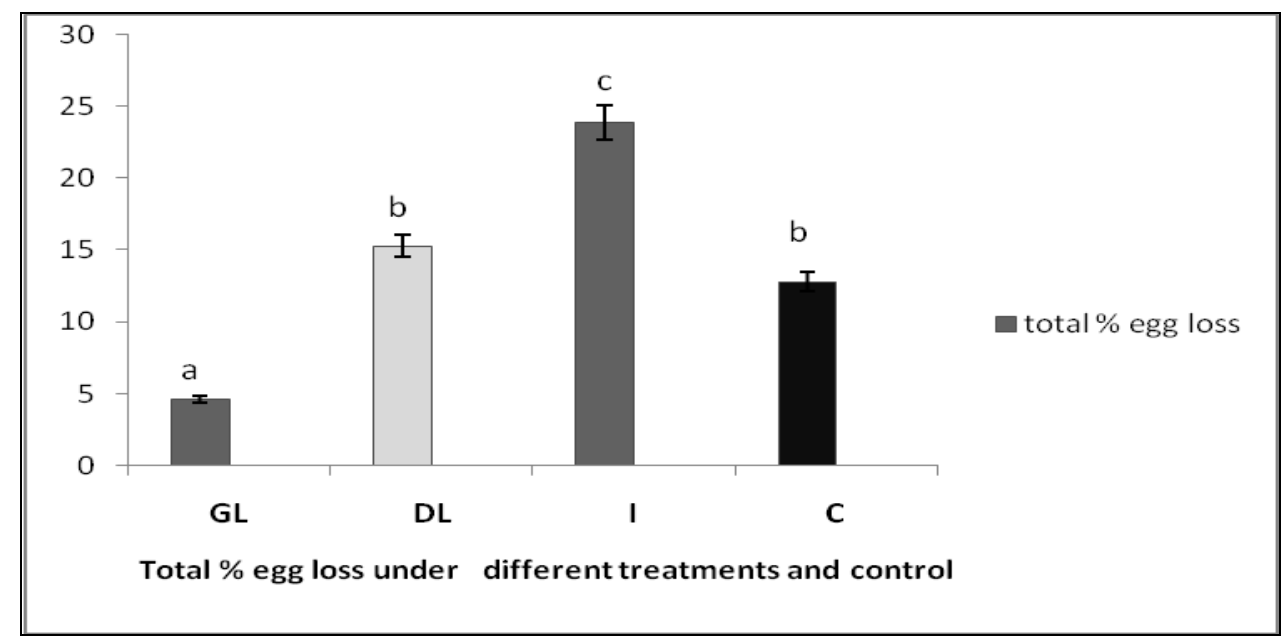

Fig.2 Water temperature variation in egg incubation trays during incubation period.

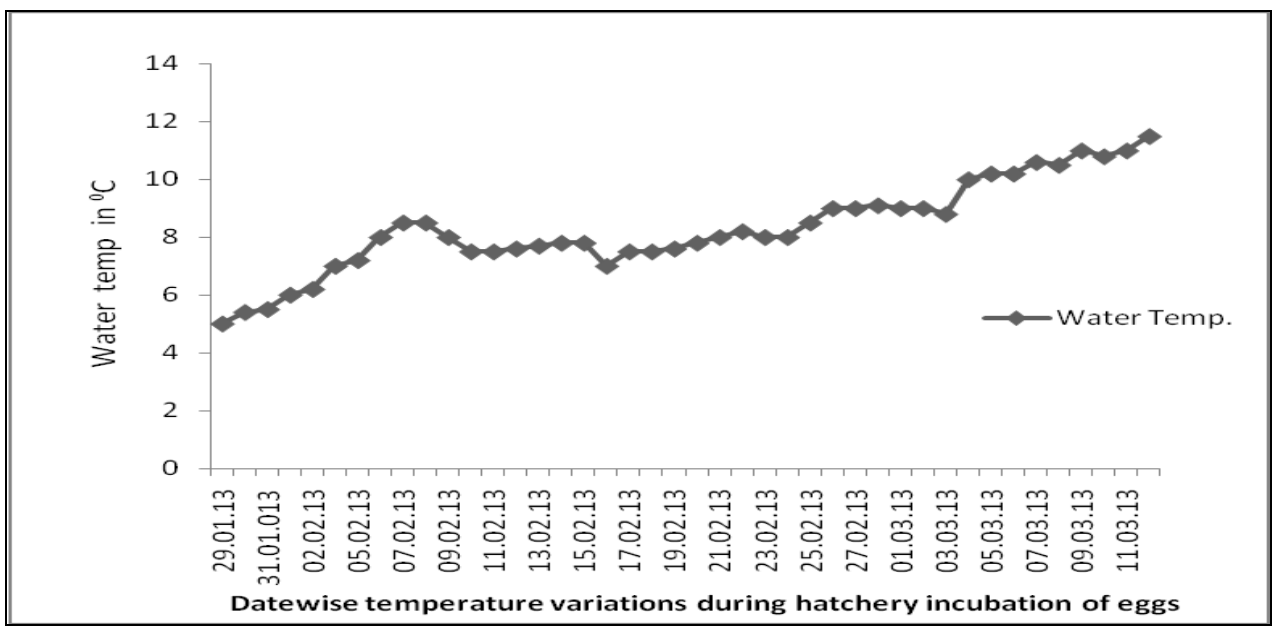

Beneficial effects of given disinfectant may get diluted with elongation of incubation period. Reports have indicated that few bacterial isolates may be inhibited at a lower iodine dose of $50 \mathrm{mg} \mathrm{L^{-1 }}$ and $30 \mathrm{mg} \mathrm{L}^{-1}$ (Cipriano et al., 2001) Water temperature during study period varied between $5-11.5{ }^{\circ} \mathrm{C}$ (Fig 2), which was well under acceptable limit and probably may not have elicited any adverse influence on egg development. According to Huet 1970, water temperature tolerance limit of rainbow trout eggs and embryo is $5-15{ }^{0} \mathrm{C}$ with optimum level of 8-14 ${ }^{0} \mathrm{C}$. Among other parameters, hardness value may also affect the normal developmental stages (Molony 2001), however, hardness was at lower side in between $20-30 \mathrm{ppm}$ and to some extant might have affected the survival of eggs in present study. Though, acceptable normal $\mathrm{pH}$ level is reported in between 6.58.0 (Huet 1970; Molony 2001), under present study $\mathrm{pH}$ was optimum and varied between 7.0-7.8 during the entire period of egg rearing while chlorides nitrate and iron values were found under tolerable limit. At the time of hatching, uniformity in release of yolk sac larvae from the eggs and shorter time durations may also be considered a sign of well being. Highest mean $\pm \mathrm{SE}$ hatching percent of $62.66 \pm 4.33$ with lower mortality in $6^{\text {th }}$ week was observed in GL treated eggs followed by $42.00 \pm 5.80$ in $C, 35.33 \pm 3.17$ in 
DL and 15.66 \pm 4.04 in iodine solution demonstrating trend similar to egg loss in above exposures presenting superiority of GL over other treatments in regards to hatching (Table 3). Literature referred has revealed that so far no studies has been made on the use of $P$. pashia leaf extract as rainbow trout egg disinfectant and this may probably be the first report in regards to use of $P$. pashia as trout egg disinfect. The plant is widely available in mid hill areas and leaf, fruits and flowers are being mainly used by wild animals. In mid hill areas, farming and seed production of rainbow trout is commonly practiced by trout grower, use of locally available suitable plant extract may save money as well as use of harmful disinfects.

In conclusion, the results of present study suggest that freshly procured shade dried green leave extract of Pyrus pashia @ 10\% could be used as egg disinfectant in rainbow trout eggs without any harmful effects on hatching under normal physicochemical parameters of hatchery water and significant higher egg survival was obtained in present study. Further detailed studies may add for use of this plant extract.

\section{Acknowledgements}

The authors are thankful to Director, ICARDirectorate of Coldwater Fisheries Research, Bhimtal for providing guidance and necessary facilities.

\section{References}

Amend D.F. 1974. Comparative toxicity of two iodophors to rainbow trout eggs. Transactions of the American Fisheries Society, 103(1):73-78.

Anon. 2009. Fish culture technical bulletin2009. Egg disinfection and incubation procedure for salmonids (Salmon, Trout and Whitefish) Ontario, Ministry of
Natural Resources Management Division, Piterborough, Canada, 9 pages.

Anon. 2013. DCFR Annual Report-2013. Directorate of Coldwater Fisheries Research, Bhimtal, 263136, Nainital, Uttarakhand, India. 14.

Bandrick A.M., Newton J.M., Henderson G. and Vickers J.A. 1967. An investigation into the interaction between Iodine and bacteria. Journal of Applied Bacteriology, 30(3):484-487.

Barker G.A., Smith S.N. and Bromage N.R. 1989. The bacterial flora of rainbow trout, Salmo gairdneri Richardson, and brown trout, Salmo trutta L., eggs and its relationship to developmental success. Journal of Fish Diseases, 12:281-293.

Barker G.A., Smith S.N. and Bromage, N.R. 1991. Commensal bacteria and their possible relationship to the mortahty of incubating salmonid eggs. Journal of Fish Diseases, 14 (2):199-210.

Bell G.R., Hoskins G.E. and Hodgkiss W. 1971. Aspects of the characterization, identification and ecology of the bacterial flora associated with the surface of stream incubating Pacific Salmon (Oncorhynchus) eggs. Journal Fisheries Research Board of Canada, 28(10):1511-1525.

Chapman P.F. and Rogers R.W. 1992. Decline in iodine concentration of iodophor during water hardening of salmonid eggs and methods to reduce this effect. Progressive Fish-Culturist, 54(2):81-87.

Cipriano R.C., Novak B.M., Flint D.E. and Cutting D.C. 2001. Reappraisal of the federal fish health recommendation for disinfecting eggs of Atlantic salmon in iodophor. Journal of Aquatic Animal Health, 13(4):320-327.

Dey R.K. and Chandra S. 1994. A new trend in fish disease management through application of herbal materials. Fishing Chimes, 14(9):19-20.

Dey R.K. and Chandra S. 1995. Preliminary studies to raise disease resistant seed (fry) of Indian major carps, Catla catla through herbal treatment of spawn. Fishing Chimes, 14(12):23-25. 
Dugenci S.K., Arda N. and Candan A. 2003. Some medicinal plants as immune stimulant for fish. J. Ethnopharmacol, 80:99-106.

FAO. 2012. Cultured aquatic species information programme. Oncorhynchus mykiss. Text by Cowx, I. G., Fisheries and Aquaculture Department.

Fowler L.G., and Banks, J.L. 1991. A safe level of iodophor for treating eggs of fall Chinook salmon during water hardening Progressive Fish-Culturist, 53(4):250-251.

Eric J.W., Ronney E.A, Eric J.B., Anna F. and Wade C. 2008. Comparison of the efficacy of Iodine, Formalin, salt, and Hydrogen Peroxide for control of external bacteria on rainbow trout eggs. North American Journal of Aquaculture, 70(2):118-127.

Forneris G., Bellardi S., Palmegiano G.B., Saroglia M., Sicuro B., Gasco L. and Zoccarato I. 2003. The use of ozone in trout hatchery to reduce saprolegniasis incidence. Aquaculture, 221(1-4):157-166.

Griffiths Elwyn. 1991. Environmental regulation of bacterial virulence implications for vaccine design and production. Trends in Biotechnology, 9(1):309-315.

Hea Jianmin., Tianpeng Yina., Yang Chenc., Le Caia., Zhigang Taid., Zhenjie Lia., Chuanshui Liua., Yarong Wangc. and Zhongtao Dinga. 2015. Phenolic compounds and antioxidant activities of edible flowers of Pyrus pashia. Journal of Functional Foods, 17:371-379.

Heikkinen J., Mustonen S.M., Eskelinen P., Sundberg L.R. and Wright Von. 2013. Prevention of fungal infestation of rainbow trout (Oncorhynchus mykiss) eggs using UV irradiation of the hatching water. Aquacultural Engineering, 55: 9-15.

Huet M. 1970. Textbook of fish culture, breeding and cultivation of fish. Surrey, UK, Fishing News (Books) Ltd, 436.

Jambey Tsering., Baikuntha Jyoti Gogoi. and Hui Tag. 2012. Ethanobotany and phytochemical analysis of Pyrus pashia leaves. IJPSR, 3(8):2721-2725.
Jeff J Racha., Steven Redmanb., Dale Basta. and Mark, P Gaikowskia. 2005. Efficacy of hydrogen peroxide versus formalin treatments to control mortality associated with saprolegniasis on Lake Trout Eggs. North American Journal of Aquaculture, 67(2):148-154.

Kimura T., Yoshimizu M., Tajima K., Ezura Y. and Sakia M. 1976. Disinfection of hatchery water supply by ultraviolet (UV) irradiation, I. Susceptibility of some fishpathogenic bacterium and microorganisms inhabiting pond waters. Bulletin of the Japanese Society of Scientific Fisheries 42:207-211.

Lin J., Opak War. and Geheeb-Keller M. 1999. Preliminary screening of some traditional Zulu medicinal plants for antiinflammatory and antimicrobial activities. Journal of Ethnopharmacolog, 68:267274.

Madhuri S., Mandloi A.K., Pandey Govind. and Sahni Y.P. 2012a. Antimicrobial activity of some medicinal plants against fish pathogens. Int. Res. J. Pharm, 3(4):28-30.

Madhuri, S and Mandloi, A K (2012b) Medicinal plants useful in fish diseases. $P l$. Arch. 12(1): 1-4.

Mark P. Gaikowski Jeff J Rach., Jeff J Olson., Rob T Ramsay. and Martha Wolgamood. 1998. Toxicity of hydrogen peroxide treatments to rainbow trout eggs. Journal of Aquatic Animal Health, 10(3):241-251.

McFadden T.W. 1969. Effective disinfection of trout eggs to prevent egg transmission of Aeromonas liquefaciens. Journal of the Fisheries Research Board of Canada, 26:2311-2318.

Mitchell A.J. and Collins C. 1997. Review of the therapeutic uses of hydrogen peroxide in fish production. Aquaculture Magazine, 23(3):7479.

Molony B. 2001. Environmental requirements and tolerances of rainbow trout (Oncorhynchus mykiss) and brown trout (Salmo trutta) with special reference to Western Australia: a review. Fisheries Research Report No. 130. Perth, Australia, Fisheries Research Division. 
Negi V.S., Maikhuri R.K. and Vashishtha D.P. 2011. Traditional healthcare practices among the villages of Rawain valley, Uttarkashi, Uttarakhand, India. Indian Journal of Traditional Knowledge 10 (3):533-537.

Pandey Srinivasan., Sangeetha D.N., Suresh T. and Perumalsamy P.L. 2001. Antimicrobial activity of certain Indian medicinal plants used in folkloric medicine. Journal of Ethnopharmacology, 4:217-220.

Ramasamy H., Balasundaram Chellan. and Heo Moon-Soo. 2011. Impact of plant products on innate and adaptive immune system of cultured finfish and shellfish. Aquaculture, 317(1-4): 1-15.

Ross A.J., and Smith C.A. 1972. Effect of two iodophors on bacterial and fungal fish pathogens. Journal of the Fisheries Research Board of Canada, 29:1359-1361.

Saklani Sarla. and Chandra Subhash. 2012. In Vitro antimicrobial activity, nutritional profile of medicinal plant of Garhwal Himalaya. IJPSR, 3(1):268-272.

Shepherd J. and Bromage N.R. 1992. Intensive fish farming. Blackwell Scientific Publications, Oxford, England, 416.

Soetan K.O., Oyekunle M.A., Aiyelaagbe O.O. and Fafunso M.A. 2006. Evaluation of the antimicrobial activity of saponins extract of Sorghum bicolor L. Moench. African
Journal of Biotechnology, 5(23):24052407.

Vass K.K. 2012. Coldwater fisheries and research status in India. In: Sarma, D., A. Pande, S. Chandra and S. K. Gupta, (eds.). Silver Jubilee Compendium on Coldwater Fisheries 25 years of Sustainable Research \& Management. Directorate of Coldwater Fisheries Research, Bhimtal, Nainital, Uttarakhand, 25-42.

Wade A.J. and Michael J.M. 2001. Effect of Idophor concentration and duration of exposure during water hardening on survival of Atlantic salmon eggs. North American Journal of Aquaculture, 63(3):229-233.

Wright L.D. and Snow J.R. 1975. Effect of six chemicals for disinfection of largemouth bass eggs. Progressive Fish-Culturist, 37(4):213-217.

West van Pieter. 2006. Saprolegnia parasitica, an oomycete pathogen with a fishy appetite: new challenges for an old problem. Mycologist, 20(3):99-104.

Woynarovich A., Hoitsy G. and Moth-Poulsen T. 2011. Small-scale rainbow trout farming. FAO Fisheries and Aquaculture Technical Paper No. 561. Rome, FAO. 2011,81 .

\section{How to cite this article:}

Ravindra and Suresh Chandra. 2017. Evaluation of Pyrus pashia Leaf Extract as a Disinfectant for Rainbow Trout (Oncorhynchus mykiss) Fertilised Eggs. Int.J.Curr.Microbiol.App.Sci. 6(1): 697-706. doi: http://dx.doi.org/10.20546/ijcmas.2017.601.084 